\title{
The natural history of multiple sclerosis: a regional study with some longitudinal data
}

\author{
D H Miller, R W Hornabrook, G Purdie
}

\begin{abstract}
A regional survey of multiple sclerosis (MS) patients in Wellington, New Zealand in 1983 identified 245 patients, giving a prevalence (all categories included) of 72 per 100000 . Retrospective review of the history and medical records identified a poorer prognosis for disability where there was progressive onset of symptoms, secondary progression after a remitting phase, older age of onset (40 years or more), or a motor syndrome involving the limbs at presentation. In 1983 follow up data were obtained on 96 patients who were seen during a previous survey in 1968. For those with definite or probable MS, progression to severe disability (Kurtzke disability status scale (DSS) 6-9) or death (DSS 10) was seen in 26/34 with moderate disability (DSS 3-5) in 1968 and in only 5/29 with mild disability (DSS 0-2). When the analysis is confined to those with symptoms for at least five years in 1968, severe disability or death from MS occurred in 22/30 with moderate and 4/19 with mild disability $\left(\chi^{2}=10.8, p=0.001\right)$. It is concluded that the patient's established disability level after five years of illness is a useful, but not infallible, prognostic indicator. From the follow up of the 1968 patients, the probability of MSrelated mortality for a given disease duration was calculated. Using this survival distribution to adjust the disability ratings in the 1983 population, it was found that the proportion with mild disability decreased steadily with increasing disease duration, reaching $14 \%$ when the disease duration was more than 25 years.
\end{abstract}

Wellington School of Medicine, University of Otago, Wellington Hospital, Wellington, New Zealand Department of Medicine D H Miller R W Hornabrook Department of Community Health G Purdie

Correspondence to: Correspondence to: Dr Miller, Institute of Hospital for Neurology and Hospital for Neurology and Square, London WCIN 3BG, UK

Received 5 November 1990 and in revised form 4 June 1991.

Accepted 9 July 1991
There have been numerous studies of the natural history of multiple sclerosis (MS). We had three principal reasons for undertaking the present one.

First, no previous natural history study had been performed in New Zealand. Whilst there is no reason to think that the clinical characteristics differ from those encountered elsewhere, this had yet to be demonstrated. Data on natural history is of immediate relevance to those involved in advising patients regarding prognosis and in evaluating the effects of therapy.

Secondly, we were in a position to obtain long term follow up data on patients who had been seen in the same region by one of the authors 15 years earlier. ${ }^{1}$ Thirdly, we felt there was a good opportunity for relatively complete case ascertainment, the failure to achieve this introducing an important bias in many previous studies. ${ }^{2}$

\section{Methods}

CROSS-SECTIONAL/REGIONAL STUDY

The study was performed within the Wellington Hospital Board region, which includes Wellington City, Hutt Valley, Porirua Basin and Kapiti Coast as far as Waikanae. The region is topographically defined by geographical features, a river and a mountain range, which create a natural watershed separating it from the rural regions to the North. The population of this region on census day, 24 March 1981, was 341 454. This was chosen as the denominator population for calculation of MS prevalence rates (prevalence day was 30 June 1983). There are three public hospitals within the region with a single Department of Neurology at Wellington Base Hospital. At the time of the survey, the region was served by five neurologists, all of whom had appointments at Wellington Hospital. Cases were recruited from the following sources: 1) review of hospital and neurology department diagnostic indices; 2) individual approach to all neurologists and general practitioners working in the region; 3) Wellington MS Society register; 4) surveillance of chronic care institutions within the Wellington region; 5) follow up of patients seen by one of the authors during a previous study in $1968 .^{1}$

All patients were seen by either DHM or RWH. Most were seen at a hospital clinic specifically arranged for the study. A number of patients were visited in their own homes or at a chronic care institution. The history of the illness was recorded in detail. The patients' recollections were supplemented by all available medical records. A neurological examination was performed in all cases.

\section{Longitudinal study}

In 1968, 139 patients (all categories) were identified in the Wellington region, giving a prevalence of $47 / 100000 .^{1}$ By 1983 , the names and original clinical records of 107 individuals were still available (all record of the remaining 32 cases had been lost during a relocation of departmental files); this group of 107 constitutes the cohort who were entered into the longitudinal study.

All 107 patients had been seen by RWH in 1968, at which time the history and examination findings were recorded in detail. In 1983, 
we obtained follow up information on 96 of these patients. By that time, 36 had died. These patients' death certificates and medical records were reviewed, and cause of death was classified as either MS-related or not. To be an MSrelated death required evidence from medical records and/or the death certificate that the primary cause of death was a recognised complication of severe MS, for example, bronchopneumonia, septicaemia with urinary tract infection. A death was classified as nonMS related when the primary cause was a separate and unrelated disorder (the two most common being cancer and ischaemic heart disease). There was insufficient information to determine immediate pre-mortem disability status among those who died of non MSrelated causes, thus this group are excluded from the follow up analyses of disability. Of the 60 who were alive in 1983, 58 were seen and examined by either DHM or RWH. Follow up information was obtained by letter in the two remaining patients. Fifty six of the 60 were still resident in the Wellington region in 1983, and are therefore included in the cross-sectional/ regional study.

From the longitudinal study, a life table of the relationship of MS-related mortality with disease duration was calculated. The table started at disease onset. Patients entered the table at their disease duration in 1968 and were withdrawn in 1983 or when a non MS-related death occurred. Using a Kaplan-Meier approach, survival curves were drawn for both the MS patients and for an age, race and sex matched group without MS (figure).

\section{Diagnosis}

MS was diagnosed using the McDonaldHalliday criteria. ${ }^{3}$ During this paper, the term "definite" MS is equivalent to "clinically definite", as defined by McDonald and Halliday. We use the terms "probable" to include both "early probable" and "progressive probable" MS, and "possible" to include both "progressive possible" and "suspected" MS.

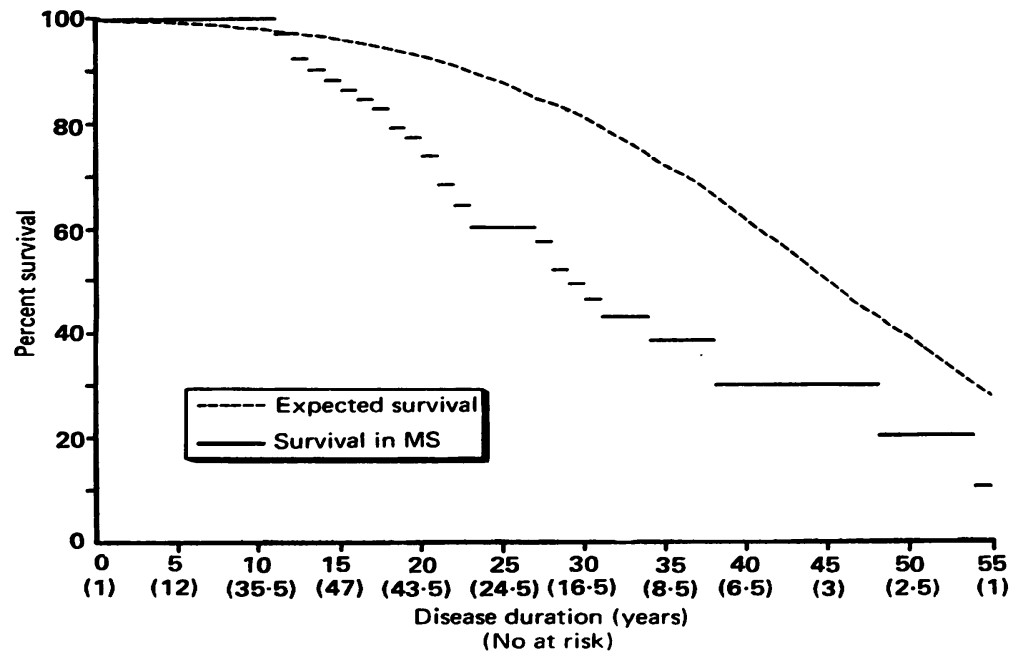

Figure Survival curve in Wellington MS patients and expected survial curve for an age, race and sex matched population without MS.
In 1983, abnormal visual evoked potentials (VEP) were accepted as paraclinical evidence of an additional lesion. The diagnostic category for the 1983 cross-sectional study took account of the VEP result. When demographic features of the 1968 and 1983 groups were compared in the longitudinal study (to determine whether the 1968 group was likely to be representative of the whole MS population), diagnostic category of the 1983 group was based on clinical features alone (table 5).

\section{Disability}

The Kurtzke disability status scale (DSS) was used to classify disability in both the 1983 and 1968 studies. ${ }^{4}$ Patients were stratified as having mild (DSS grade 0-2), moderate (DSS grade 3-5) or severe (DSS grade 6-10) disability (DSS grade 10 is also referred to as an MSrelated death).

\section{Statistical analysis}

For the cross-sectional regional study, differences in disability status were examined using analysis of covariance adjusting for disease duration as the covariate. The ranks of the disability status were used in the analysis to perform non-parametic tests. ${ }^{5}$ Differences in the age of onset between the sexes in the 1983 population, in demographic features of the 1968 and 1983 populations, and in the follow up of the 1968 population were examined using Wilcoxon rank sum, Chi-squared and Fisher's exact tests.

\section{Results}

A) CROSS-SECTIONAL/REGIONAL STUDY

We found $245 \mathrm{MS}$ patients living in Wellington on 30 June 1983 (in an earlier paper concentrating on ethnic and HLA patterns, we reported 237 cases for the same prevalence day; ${ }^{6}$ on subsequently reviewing our files for this study, we found a small number of cases which had not been included in the earlier paper). Incorporating the VEP result (performed in 123 cases), there were 155 with definite, 54 with probable and 36 with possible MS (on clinical grounds alone, there were 139 with definite, 67 with probable and 39 with possible MS). The crude prevalence for all cases is $72 / 100000$; that for patients with definite or probable $M S$ is $61 / 100000$. The analyses which follow are confined to the 209 patients with definite or probable MS.

There were 60 males and 149 females (ratio $1: 2 \cdot 5)$. Mean age of onset was $32 \cdot 2$ years - this was slightly higher in males ( 33.9 years) than in females ( 31.5 years), but the difference is not significant (Wilcoxon rank sum test $p=$ 0.08 ). The range of ages of onset was $15-58$ years. In $68.4 \%$, onset of symptoms occurred between 20 and 39 years of age. Thirteen patients $(6 \cdot 2 \%)$ had onset of symptoms at the age of 50 years or more. The mean disease duration was 14.8 years (range $1-47$ years).

The overall distribution of severity on the Kurtzke scale reveals a bimodal distribution, similar to that reported by others, ${ }^{7}$ with peaks at DSS1 and DSS7 (table 1); 46.4\% had mild, 
Table 1 Disability status of the 1983 MS population*

\begin{tabular}{lc}
\hline$D S S$ & Number of patients \\
\hline 0 & 3 \\
1 & 58 \\
2 & 36 \\
3 & 29 \\
4 & 20 \\
5 & 7 \\
6 & 14 \\
7 & 23 \\
8 & 12 \\
9 & 7 \\
\hline *clinically definite or probable MS only
\end{tabular}

Table 21983 MS population: relationship of disability to disease duration *

\begin{tabular}{|c|c|c|c|c|c|c|}
\hline & \multicolumn{6}{|c|}{ Duration (years) } \\
\hline & $1-5$ & $6-10$ & $11-15$ & $16-20$ & $21-25$ & $>25$ \\
\hline $\begin{array}{l}\text { DISABILITY } \\
\text { Mild } \\
\text { (\% mild) } \\
\left(\% \text { mild }{ }^{\star \star}\right) \\
\text { Moderate } \\
\text { Severe } \\
(\% \text { severe) } \\
\left(\% \text { severe }{ }^{\star \star}\right)\end{array}$ & $\begin{array}{l}35 \\
(83) \\
(83) \\
6 \\
1 \\
(2) \\
(2)\end{array}$ & $\begin{array}{l}23 \\
(46) \\
(46) \\
13 \\
14 \\
(28) \\
(28)\end{array}$ & $\begin{array}{l}12 \\
(43) \\
(41) \\
7 \\
9 \\
(32) \\
(34)\end{array}$ & $\begin{array}{l}11 \\
(35) \\
(32) \\
10 \\
10 \\
(32) \\
(39)\end{array}$ & $\begin{array}{l}8 \\
(30) \\
(23) \\
9 \\
10 \\
(37) \\
(52)\end{array}$ & $\begin{array}{l}8 \\
(26) \\
(14) \\
11 \\
12 \\
(39) \\
(66)\end{array}$ \\
\hline
\end{tabular}

^clinically definite or probable MS

$\star \star$ these are the adjusted proportions, after the addition to the severe disability group of the estimated number of MS-related deaths for a given disease duration (based on the mortality rates calculated in the longitudinal study).

$26 \cdot 8 \%$ moderate and $26 \cdot 8 \%$ severe disability.

The proportions with severe disability were very low in those with not more than five years of illness ( $2 \%$, table 2$)$, increasing sharply to $28 \%$ in those with disease of duration six to 10 years. Thereafter, there was a steady but small increase in the proportions with severe disability with increasing disease duration, reaching 39\% with duration more than 25 years. Mild disability was present in $35 \%$ with disease duration 16-20 years, in 30\% with duration 21-25 years, and in $26 \%$ with duration more than 25 years.

However, these proportions, being derived from a cross-sectional study, do not take account of patients who have already died from MS. To adjust for this, we used the life table of MS-related mortality versus disease duration calculated from the longitudinal study (see methods; results section B). Using this adjustment, the estimated proportions with mild disability are $32 \%$ at $16-20$ years disease duration, falling to $23 \%$ at $21-25$ years, and only $14 \%$ after more than 25 years. Conversely, severe disability or death from MS is calculated to occur in 39\% after 16-20 years, $52 \%$ after $20-25$ years, and $66 \%$ after more than 25 years.

Eleven (5.3\%) patients had a gradually progressive onset of symptoms (primary progressive MS) and there was significantly more disability in these patients $(73 \%$ had severe disability, $p<0.0001$ adjusted for disease duration). The remainder had an acute or subacute onset of symptoms typically with subsequent remission to some degree, although occasionally with a persistent stable deficit. At the time of assessment, secondary progression had developed in $63(30.1 \%)$, while $135(64.6 \%)$ were still in the relapsing- remitting phase. The development of secondary progressive disease was associated with greater disability- $68 \%$ had severe disability, compared with only $4 \%$ of those still in the relapsing-remitting phase $(\mathrm{p}<0.0001$ adjusted for disease duration).

Among those whose onset of symptoms was at or above the age of 40 , there was significantly more disability $(\mathrm{p}=0.003$ adjusted for disease duration; table 3 ). There was a nonsignificant trend towards more disability in males $(\mathrm{p}=0 \cdot 16)$.

There was significantly more disability in those who presented with a motor syndrome involving the limbs, either in isolation or in conjunction with sensory disturbances (table 4). Although only small numbers presented with a cerebral hemisphere or cerebellar disorder, 4 of 7 in the former category and 3 of 5 in the latter, had severe disability on prevalence day. Severe disability was present in a smaller proportion of those whose first symptoms were optic neuritis or sensory disturbance in the limbs, but the difference was not statistically significant.

The number of relapses in the first three years of illness did not have a significant effect on the long term course when comparing three groups-those with 0,1 , or greater than 1 relapses $(p=0.20$ adjusted for disease duration).

B) LONGITUDINAL STUDY

Of the 107 patients seen by RWH in 1968, 76 were classified as definite or probable and 31 as possible MS. Major clinical and demographic features of the 1968 definite/probable cases are shown in table 5. There was no significant difference between the 1968 and 1983 definite/ probable cohorts (the latter classified without VERs) in terms of age of onset (Wilcoxon rank sum test, $\mathrm{p}=0.88)$, sex ratio $\left(\chi^{2}=0 \cdot 29, \mathrm{p}=\right.$ 0.59 ), disability (Wilcoxon rank sum test, $\mathrm{p}=$ 0.62 ) or duration of illness (Wilcoxon rank sum test, $\mathrm{p}=0.48)$.

In $1983,6 / 76(8 \%)$ with definite or probable

Table 31983 MS population: relationship of age of onset with disability

\begin{tabular}{lllll}
\hline \multicolumn{5}{c}{ Age of onset (years) } \\
\cline { 2 - 5 } & 20 & $20-29$ & $30-39$ & $>40$ \\
\hline DISABILITY & $7(44 \%)$ & $38(54 \%)$ & $38(54 \%)$ & $14(28 \%)$ \\
Mild & $3(19 \%)$ & $15(21 \%)$ & $16(23 \%)$ & $22(44 \%)$ \\
Moderate & $6(38 \%)$ & $20(27 \%)$ & $16(23 \%)$ & $14(28 \%)$ \\
Severe & 6 & &
\end{tabular}

Table 41983 MS population: influence of presenting syndrome on the course of the disease

\begin{tabular}{llll}
\hline Presenting syndrome & Number & $\%$ Severe & p-value \\
\hline Optic Neuritis & 43 & 19 & 0.06 \\
Brain stem & 48 & 25 & 0.17 \\
Limb sensory & 56 & 16 & 0.10 \\
Limb motor & 29 & 45 & 0.005 \\
Limb sensorimotor & 19 & 53 & 0.01 \\
Cerebral & 7 & 57 & 0.12 \\
Cerebellar & 5 & 60 & 0.004 \\
\hline
\end{tabular}

*The value given represents the statistical significance of the difference in disability between those with the given presenting syndrome and all other patients. In all cases, the p-value has been corrected for differences in disease duration. 
Table 5 Demographic data on definitelprobable MS patients seen in 1968 and $1983^{*}$

\begin{tabular}{|c|c|c|}
\hline & 1968 & 1983 \\
\hline $\begin{array}{l}\text { Male:female } \\
\text { Age of onset (years) }\end{array}$ & $19: 57(1: 3)$ & $60: 146(1: 2 \cdot 4)$ \\
\hline $\begin{array}{l}\text { mean } \\
\text { range }\end{array}$ & $\begin{array}{l}32 \cdot 4 \\
10-57\end{array}$ & $\begin{array}{l}32 \cdot 1 \\
15-58\end{array}$ \\
\hline $\begin{array}{l}\text { Disease duration (years) } \\
\text { mean } \\
\text { range }\end{array}$ & $\begin{array}{l}14 \cdot 3 \\
1-48\end{array}$ & $\begin{array}{l}15 \cdot 0 \\
1-47\end{array}$ \\
\hline $\begin{array}{l}\text { Severity } \\
\text { mild } \\
\text { moderate } \\
\text { severe }\end{array}$ & $\begin{array}{l}31(41 \%) \\
34(45 \%) \\
11(14 \%)\end{array}$ & $\begin{array}{l}94(46 \%) \\
56(27 \%) \\
56(27 \%)\end{array}$ \\
\hline $\begin{array}{l}\text { Number with mild disease } \\
\text { after } 15 \text { years }\end{array}$ & $9 / 26(35 \%)$ & $27 / 89(30 \%)$ \\
\hline
\end{tabular}

ॠVER not used in classification of 1983 patients.

MS, and 5/31 (16\%) with possible MS were lost to follow up. Of those with definite or probable MS who were lost to follow up, $5 \mathrm{had}$ mild and 1 had moderate disability in 1968 .

1983 classification of the 31 patients with possible MS in 1968

By 1983, 9 had developed definite MS, 4 had developed probable MS, 8 still had possible MS, 1 had died of an MS-related death, 4 had died of a non-MS related death, and 5 were lost to follow up.

FOLLOW UP OF PATIENTS WITH SYMPTOMS FOR AT LEAST FIVE YEARS IN 1968 (TABLE 6)

The analysis was confined to patients who in 1968 already had definite or probable MS, or who in 1968 had possible MS and in 1983 were classified as definite or probable MS (those who had possible MS in both 1968 and 1983 are excluded from this analysis to reduce bias due to cases who do not in fact have MS). Looking at just those patients in whom follow up data relating to disease severity was available, only $4 / 19(21 \%)$ with mild disability in 1968 had become severely disabled (including 1 MS-related death) by 1983 ; whereas $22 / 30$ (73\%) with moderate disability in 1968 had become severely disabled or died from the disease by 1983 . The difference in outcome between those with mild and moderate MS in 1968 is significant $\left(\chi^{2}=10 \cdot 8, \mathrm{p}=0.001\right)$.

There was no difference in the frequency of non-MS related deaths in each group (Fisher's exact test $p=0.70$ ), but 5 with mild MS in 1968 were lost to follow up compared with only one in the more disabled groups.

FOLLOW UP OF PATIENTS WITH SYMPTOMS FOR LESS THAN FIVE YEARS IN 1968 (TABLE 7)

The analysis is again confined to patients who had definite or probable MS either in both

Table 61983 Disability of patients wlth symptoms for at least 5 years in 1968

\begin{tabular}{llllllll}
\hline & \multicolumn{1}{c}{1983} & $D S S$ & & & \\
\cline { 2 - 7 } & $0-2$ & $3-5$ & $6-9$ & 10 & $\begin{array}{l}\text { Non-MS } \\
\text { death }\end{array}$ & $\begin{array}{l}\text { Lost } \\
\text { to FU }\end{array}$ \\
\hline 1968 DSS & 8 & 7 & 3 & 1 & 4 & 5 \\
$0-2$ & 1 & 7 & 11 & 11 & 4 & 1 \\
$3-5$ & 0 & 0 & 3 & 6 & 1 & 0 \\
$6-9$ & FU = follow up. & & & & &
\end{tabular}

Table 71983 Disability of patients with symptoms for less than 5 years in 1968

\begin{tabular}{lllllll}
\hline \multicolumn{1}{c}{1983} & $D S S$ \\
\cline { 2 - 7 } & $0-2$ & $3-5$ & $6-9$ & 10 & $\begin{array}{l}\text { Non-MS } \\
\text { death }\end{array}$ & $\begin{array}{l}\text { Lost } \\
\text { to FU }\end{array}$ \\
\hline 1968 DSS & 6 & 3 & 1 & 0 & 2 & 0 \\
$0-2$ & 0 & 0 & 2 & 2 & 0 & 0 \\
$3-5$ & 0 & 0 & 0 & 1 & 0 & 0 \\
$6-9$ & FU = follow up. & & & & &
\end{tabular}

studies or by 1983 . These individuals are significant in that they were followed longitudinally from close to the onset of their illness. Not surprisingly, the majority of these patients had only mild disability in $1968(12 / 17 ; 71 \%)$. $6 / 17(35 \%)$ were severely disabled or had died of MS by 1983. Amongst patients in whom follow up data on disease severity was available, only $1 / 10$ with mild disability, but all 4 with moderate disability, were severely disabled or dead from MS by 1983. This difference was statistically significant $(p=0.005$, Fisher's exact test).

\section{Mortality rate}

Of the entire definite/probable MS cohort (as classified in both studies or in 1983 alone) in whom follow up data were available, $32 / 84$ had died during the 15 year interval. Twenty one deaths were MS related, and 11 were not. The expected mortality for a group with the same race, age and sex distribution but without MS was $14 \cdot 1$ deaths (calculated from New Zealand Life Tables $1980-82){ }^{8}$

Death from MS was seen in $1 / 35(3 \%)$ with mild disability in $1968,13 / 38$ (34\%) with moderate disability, and $7 / 11$ (64\%) with severe disability. There were no MS-related deaths in the first 10 years of the disease. By 15 years disease duration, the chance of an MSrelated death was $5 \%$, by 20 years $15 \%$, by 25 years $27 \%$, and at 30 years it was $43 \%$. The cumulative survival curve for our MS patients and the expected survival curve in an age, race and sex matched group without MS are displayed in the figure.

\section{Discussion}

Weinshenker and Ebers ${ }^{2}$ have reviewed methodological difficulties which arise in studies of the natural history of MS. These include the difficulty in recruiting patients from onset of the illness; the frequent lack of longitudinal follow up data over a duration appropriate to the disease evolution; bias towards unusual or severe cases in tertiary centres; loss of institutionalised patients to follow up; and uncertainty as to the best parameter to measure outcome.

For a number of reasons, we feel that the present cross-sectional study was successful in detecting a high proportion of MS cases living in Wellington in 1983. First, one of the authors (RWH) had been seeing a large cohort of MS patients within the region for over 20 years, and had undertaken a prevalence study 15 years earlier. Secondly, there was excellent 
cooperation in the referral of cases by the five neurologists who practised in the region at the time of the study. Thirdly, there was a single regional neurological service at Wellington Hospital, and it would be exceptional for patients to have gone outside of the region for their primary neurological assessment. Fourthly, community visits were undertaken to patients who were unable or unwilling to come to the clinic for the study.

Most findings in our cross-sectional study accord well with other studies. The sex ratios, ages of onset and patterns of clinical presentation are very typical. Rather a small percentage of our patients had primary progressive disease (5.3\%; $95 \%$ confidence intervals (CI) 2.8-9.5\%) - other studies have reported this onset in $8-33 \% .^{79-11}$ We often found that, on carefully reviewing the medical files or taking the history, there had been a transient episode of neurological disturbance, with remission, before progressive deterioration.

A little over one third of our patients in the cross-sectional study had a favourable course with minimal disability after $15-20$ years, similar to the findings of McAlpine, ${ }^{12}$ and of Poser et al $^{13}$ in a community group. Even after more than 25 years of illness, about onequarter of our patients had mild disability. However, the lack of a substantial change in the proportions with mild or severe disability after about 15 years is misleading, because as already discussed, deaths due to MS were not recorded in this cross-sectional study-the same limitation applies in other cross sectional studies. As we see from the longitudinal study, death from the disease was not uncommon over a 15 year period once there was an established moderate or severe disability. We thus made an adjustment for MS-related deaths based on the longitudinal study mortality data. Applying this adjustment, it was estimated that there would still be about onethird of patients with mild disability after 15-20 years, although this proportion fell to about one-seventh after more than 25 years of illness.

In the literature, a variety of factors has been associated with the subsequent prognosis for disability, some more consistently than others. McAlpine ${ }^{12}$ reported a worse outcome in those with lower limb weakness or cerebellar signs at presentation, and a better outcome if the presentation was optic neuritis, or a brainstem or posterior column disturbance. Confravreux et al ${ }^{10}$ found greater disability where there was a short interval between the first two relapses, with an older age of onset and with development of progressive deterioration. Poser et $\mathrm{al}^{14}$ recorded a more favourable outcome when the onset was at a younger age, with optic neuritis as the presenting feature, and where the disease followed a remitting course. Visscher et $\mathrm{al}^{15}$ identified a poorer outcome with older age of onset, motor weakness (without sensory disturbance), and impaired co-ordination. Thompson et al $^{16}$ established a better outlook where there was a younger age of onset, and a long interval of the first remission; the outlook was worse where there was limb weakness at onset or progressive disease. Finally; Phadke ${ }^{11}$ reported a shorter survival period in those with severe disability at a point in time, a cerebellar disturbance at onset, a short first remission, a primary or secondary progressive course, and an older age of onset. The factors which in our cross-sectional study were found to influence the subsequent course of the disease (progressive onset or secondary progression, a motor syndrome at onset, age of onset), have thus been noted previously.

The longitudinal study is of interest in providing prospective clinical information over an unusually long period (15 years). Although longitudinal follow up was possible only in the cohort with preserved 1968 records, the major demographic features in this cohort were similar to those found in the whole 1983 MS population, at which time ascertainment was relatively complete. Thus, we consider the longitudinal group to be reasonably representative of the general MS population.

Kurtzke et al $^{17}$ followed up a group of US veterans with MS. He found that of those with mild disability after five years (DSS 0-2), only $7 \cdot 5 \%$ and $11.4 \%$ had developed severe disability after 10 and 15 years of disease respectively. Conversely, of those with moderate disability (DSS 3-5) after five years, $50 \%$ remained unchanged and $50 \%$ had become severely disabled or died from MS by 15 years.

The findings of this study are very similarof those who in 1968 had MS for five or more years with mild disability, only $21 \%$ (95\% CI 6-46\%) had developed severe disability 15 years later. On the other hand, if moderate disability was present after at least five years of illness in 1968, over the next 15 years, 73\% (95\% CI 54-88\%) developed severe disability or died from MS. Similar outcomes were observed in patients with mild or moderate disability who had had symptoms for less than five years in 1968; however, because there were only 17 patients in this group, it would be unwise to draw firm conclusions from this result.

While the difference in outcome between those with mild and moderate disability after five years of illness is highly significant, it should be noted that 5 patients with mild disability in 1968 were lost to follow up compared with only one with moderate disability. However, even if these 5 had all developed severe disability by 1983, the difference between the groups would still be significant $(9 / 24$ vs $22 / 30, p=0.02)$. If, on the other hand, none of the five had become disabled, the difference between the groups would be even greater $(4 / 24$ vs $22 / 30, p=0.0002)$. Therefore, we think that the difference in prognosis between the two groups is real. The more complete follow up of the more severely disabled groups probably reflects the loss of mobility of such individuals, and their greater need to stay under medical observation.

Among the patients who were followed longitudinally, the overall annual mortality rate was $3.0 \%$, which accords fairly well with other studies which have reported rates varying from 1.3 to $4 \% .{ }^{18-20}$ We found that $66 \%$ (95\% CI 
$47-81 \%$ ) of deaths were MS-related, similar to the figure of $62 \%$ reported in a much larger study. ${ }^{11}$ Phadke $^{11}$ also found a much lower probability of survival over a 10 year period in patients with severe disability, and our own observations concur with this. The survival curve in our MS patients is similar to that reported recently by Poser $e t$ al. $^{21}$

What can we derive from the present and other natural history studies of MS for counselling our patients at time of diagnosis? First, it can be said that a sizable proportion of patients (about a third) will be free of significant disability after about 15 years; however, after a longer period (more than 25 years), this proportion is smaller-perhaps about oneseventh. Secondly, a moderately optimistic prognosis can be given to the younger patient (age less than 40 years), whose initial episode was optic neuritis or an isolated sensory disturbance of spinal cord origin. The outlook is generally worse for those with older age of onset, motor or cerebellar features at presentation, or progressive onset of disease. Thirdly, the present study and that of Kurtzke et $a l,{ }^{17}$ suggest that the clinical disability after five years of illness is perhaps the most reliable predictor of long term outcome that is currently available. It must be recognised, however, that predictions are never certain in any individual case.

We are grateful to Dr JD Bergin, Dr LF Hass, Dr D Fung and Prof RH Johnson for referring their patients. The study was supported in part by a grant from the New Zealand MS Society.

1 Hornabrook RW. The prevalence of multiple sclerosis in New Zealand. Acta Neurologica Scandinavica 1971;47: 426-38.
2 Weinshenker BG, Ebers GC. The natural history of multiple sclerosis. Canadian fournal of Neurological Sciences 1987; 14:255-61.

3 McDonald WI, Halliday AM. Diagnosis and classification of multiple sclerosis. Br Med Bull 1977;3:4-8.

4 Kurtzke JF. On the evaluation of disability in multiple sclerosis. Neurology 1961;11:686-94.

5 Conover WJ, Imam RL. Rank transformations as a bridge between parametric and nonparametric statistics. American Statistician 1981;35:124-29.

6 Miller DH, Hornabrook RW, Dagger J, Fong R. Ethnic and HLA patterns related to multiple sclerosis in Wellington, New Zealand. $f$ Neurol Neurosurg Psychiatry 1986; 49:43-6.

7 Weinshenker BG, Bass B, Rice GPA, et al. The natural history of multiple sclerosis: a geographically based study. 1. Clinical course and disability. Brain 1989;112: 133-46.

8 New Zealand Life Tables 1980-82. Department of Statistics, Wellington, 1986.

9 Shibasaki H, McDonald WI, Kuroiwa Y. Racial modifications of clinical picture of multiple sclerosis: comparison between British

10 Confavreux C, Almard G, Devic M. Course and prognosis of multiple sclerosis assessed by the computerized data processing of 349 patients. Brain 1980;30:281-300.

11 Phadke JG. Survival pattern and cause of death in patients with multiple sclerosis: results from an epidemiological survey in north east Scotland. $\mathcal{f}$ Neurol Neurosurgery Psychiatry 1987;50:523-31.

12 McAlpine $\mathrm{D}$. The benign form of multiple sclerosis. A study based on 241 cases seen within three years of onset and followed up until the tenth year or more of the disease. Brain 1961;84:186-203.

13 Poser S, Bauer HJ, PoserW. Prognosis of multiple sclerosis. Results from an epidemiological area in Germany. Acta Neurol Scand 1982;65:347-54.

14 Poser S, Raun NE, Poser W. Age at onset, initial symptomatology, and the course of multiple sclerosis. Acta Neurol tology, and the course
Scand 1982;66:355-62.

15 Visscher BR, Liv K-S, Clarke VA, Detels R, Malmgren RM, Dudley PJ. Onset of symptoms as predictors of mortality and disability in multiple sclerosis. Acta Neurol Scand 1984;70:321-8.

16 Thompson AJ. Hutchison M, Brazil J, Feighery C, Martin EA. A clinical and laboratory study of benign multiple sclerosis. $Q \mathcal{F}$ Med, New Series 1968;58:69-80.

17 Kurtzke JF, Beebe GW, Nagler B, Kurland LT, Auth TL. Studies on the natural history of multiple sclerosis-8. Early prognostic features of the later course of the illness. fChron Dis 1977;30:819-30.

18 Kurtzke JF, Auth TL, Beebe GW, et al. Survival in multiple sclerosis. Trans Am Neurol Assoc 1969;94:134-9.

19 Gudmundsson KR. Clinical studies of multiple sclerosis in Iceland-a follow up of previous survey and reappraisal. Iceland-a follow up of previous survey and
Acta Neurol 1978;47(supp48):1-53.

20 Leibowitz U, Kahana E, Alter M. Survival and death in multiple sclerosis. Brain 1969;92:115-30.

21 Poser S, Kurtzke JF, Poser W, Schlaf G. Survival in multiple sclerosis. $\mathcal{f}$ Clin Epidemiol 1989;42:159-68.

\section{Neurological stamp}

\section{Johanne Weyer (Wier) 1515-88}

Weyer, a Dutch physician and surgeon opposed the persecution of witches. He did not accept that humans could be transformed into animals and that witches flew through the air on broomsticks. He maintained that witches were merely people who had lost control of their emotions, and their minds had become distorted with hallucinations.

At the time belief in witches was widespread. The inquisitors Sprenger and Kramer published their infamous Malleus Maleficarum in 1485, a penal code that regulated the punishment of those who practiced witchcraft. As a result countless patients with psychiatric disorders were tortured and burnt. The crusade against the hunting and burning of witches was started by Johannes Weyer in his book De Praestigiis Daemonum. Weyer's book undoubtedly saved the lives of mentally ill men and women who would have otherwise died in shackles or at the stake. Weyer has been called the founder of modern psychiatry. This stamp was issued by The Netherlands in 1960. (Stanley Gibbons No 899 , Scott No 384)

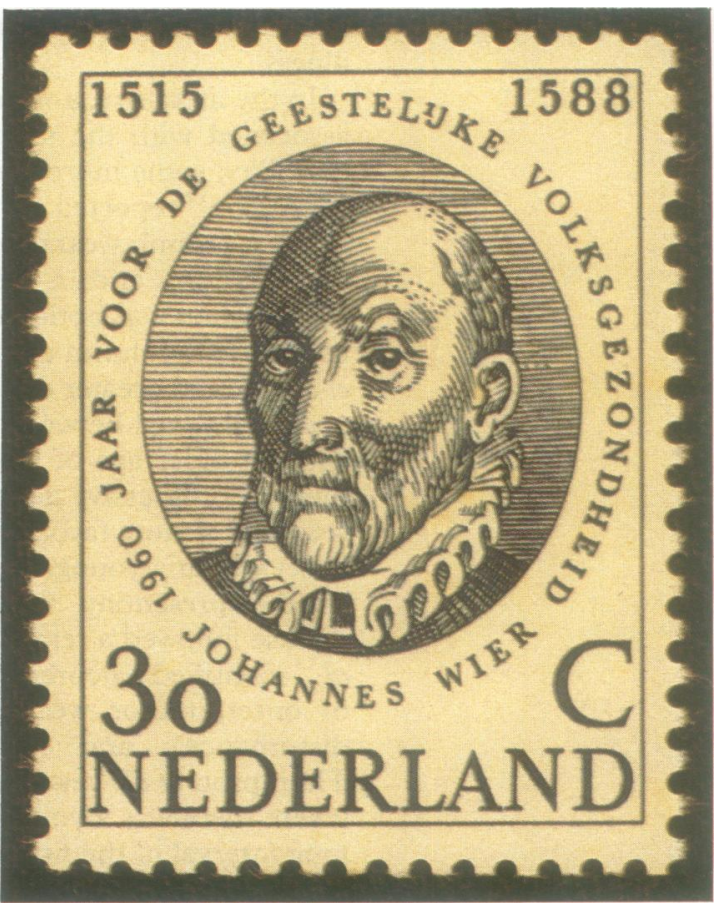

